\section{Ein Fall von Lymphextravasat nach subkutaner Contusion des Oberschenkels. ${ }^{1}$ )}

Von Dr. C. Schindler in Berlin.

Mehr als jemals früher muss heute ein jeder Arzt auch über die seltensten Erkrankungen sich gutachtlich äussern. Es erscheint mir daher gerechtfertigt, die Erinnerung an das Lymphextravasat nach subkutaner Contusion, das nicht eben häufig beobachtet und beschrieben ist, durch einen neuerdings von mir beobachteten Fall wieder aufzufrischen. Es kann nicht meine Aufgabe sein, alles zu wiederholen, was Gussenbauer darüber in seinem bedeutenden Buche: "Die traumatischen Verletzungen" geschrieben hat, und ich werde über die Ursache und die Merkmale der Krankheit nur so viel sagen, als zum Verständniss des von mir beobachteten Falles erforderllich ist. Lymphextravasate sind Ansammlungen von Lymphserum zwischen Haut und oberflächlicher Faszie in Folge einer Zerreissung der Lymphgefässe im subkutanen Fettgewebe. Die Entstehungsursache dieser Extravasate ist eine typische. Durch einen mehr oder weniger tangential wirkenden Druck auf die Haut wird die Haut von der oberflächlichen Faszie abgehoben und durch ihre Abrollung an einem festen Gegenstande (Schienengeleise) die Zerreissung der feinen Lymphgefässe bewirkt. Der Druck ist so oberflächlich, dass eine tiefere Quetschung der Gewebe nicht erfolgt und keine Blutungen in die Haut oder Muskeln entstehen, vielmehr scheint eine Verletzung überhaupt nicht entstanden

1) Vorgetragen im Berliner bahnärztlichen Verein. zu sein. Erst nach einiger Zeit, wenn sich genïgend Lymphserum ans den zerrissenen Gefässen angesammelt hat, entsteht eine kleine weiche Geschwulst, die langsam immer mehr ind mehr zunimmt, bis oft eine Ausdehnung von 2\%. Handbreite erreicht ist, indem die Lymphflïssigkeit nicht gerinnt und resorbirt wird. Die Haut bleibt schlaff, die Fluktuation ist eine grosswellige, schwappend, als ob man auf eine mit Flüssigkeit gefüllte Schweinsblase schlägt. Die Puñktion ergiebt klare Lymphe ohne Beimischung von Blut. Das Extravasat rezidivirt mehrmals, bevor es gelingt, durch eine kïnstlich erzeugte adhäsive Entziindung die Lymphgefässe zım Verschluss zu bringen. Der von mir beobachtete Fall war folgender:

Der 54 Jahre alte gesunde Arbeiter R. wollte eine sich vorwärtsbewegende Lowry mit einer stehenden verkuppeln, als er plötzlich hinstürzte, sodass er mit dem Rücken quer über den Schienen lag. Die rollende Lowry schob mit dem einen Rade den Körper, ihn an der rechten Hüfte treffend, vorwärts, wobei der Körper sich drehte und die linke Hüfte über die Schienen rollte.

An der rechten Hüfte bestanden Hautabschürfungen und stärkere Quetschungen der Gewebe, an der linken Hüfte war nichts zu bemerken. Nachdem die Quetschung der rechten Hüfte geheilt war, trat, wie der Patient meinte, von selbst, am linken Oberschenkel im obersten Drittel eine weiche Geschwulst auf, die sich zunehmend vergrösserte und deren Punktion seröse Flüssigkeit, Lymphserum ohne Beimengung von Blut ergab. Trotz dreimaliger Punktion nahm die Geschwulst immer mehr und mehr zu und erreichte eine Ausdehning von 1 $1 \frac{2}{2}$ Handtellerbreite unterhalb des Ligamentum Poupartii hin. Als ich den Kranken dem Chirurgencongress vorstellen wollte, hatte er inzwischen das Krankenhaus in Britz aufgesucht, dessen dirigirender Arzt mir iiber den dortigen Verlanf liebenswïrdiger Weise folgende Mittheilungen machte: Am 29. März 1902 wurde die schwappend fluktuirende Geschwnlst mit mittelstarkem Troikart punktirt und $100 \mathrm{ccm}$ Flüssigkeit entleert. Ausspïlung mit $2 \%$ iger Karbollösung und nachfolgender Kochsalzlösiung. Dann Compressionsverband. Am 5. April 1902 Hant fest, keine Schwellung mehr, keine Fluktuation. 15. April geheilt entlassen. Jedoch war nach einigen Wochen ein Rezidiv eingetreten. Jetzt wurde eine Inzision in der ganzen Länge der Geschwulst gemacht und diurch Karbolausspülung, Tamponade und Druckverband die Wunde zur Heilung gebracht. Ein neues Rezidiv erfolgte bis heute nicht mehr. 